\title{
Student Pharmacists' Assessment of a Serious Game on Opioid Medication Safety
}

\author{
Olufunmilola Abraham, PhD, MS, BPharm ${ }^{1}$; Maeleigh Tidd, BS ${ }^{1}$; Megan Buechel, BS ${ }^{1}$; Tanvee Thakur, MS, BPharm'; \\ Randall Brown, MD, PhD, FASAM ${ }^{2}$ \\ ${ }^{1}$ University of Wisconsin-Madison School of Pharmacy; ${ }^{2}$ University of Wisconsin-Madison School of Medicine and Public Health
}

\begin{abstract}
Objective: To explore second-and third-year student pharmacists' perspectives on the design and use of a digital game to teach opioid medication safety. To explore the game-based learning approach to teach about appropriate drug use and pediatric education.

Innovation: The lead author developed MedSMART: Adventures in PharmaCity, an educational video game focused on adolescent opioid safety. Second-and third-year students in a Midwestern School of Pharmacy enrolled in an elective course focused on appropriate use of abused drugs, played the digital game during a classroom session on adolescent opioid misuse. Using a small group discussion guide, students summarized their reflections and perspectives on gameplay.

Critical Analysis: Students retained fundamental messages of the game including opioid safety and identified that social interactions contribute to decision-making and consequences of opioid misuse. Student pharmacists found the game's visual appearance engaging, dialogue amusing, and the settings and scenarios relatable. Feedback regarding game controls, environment, dialogue, instructions, and level summaries was provided by students to improve the game design and content. This project provides an example of a thoughtful approach to game-based learning in pharmacy classrooms with the purpose of enhancing student pharmacists' knowledge about opioid safety education, communication, social collaboration, and critical-thinking.

Next Steps: Future projects can further investigate student pharmacists' preferences of using game-based active learning. Additionally, retention rates of students from joint lectures and game-based learning activities can be analyzed.
\end{abstract}

Keywords: Student pharmacists; Active learning; Prescription opioids; Medication safety: Educational games

\section{DESCRIPTION OF THE PROBLEM}

With the opioid epidemic becoming a leading public health crisis in the United States, it is imperative that it can be effectively managed by health care professionals. Of health care professionals, pharmacists play a key role, acting as an easily accessible medication expert within the community. An important population within the community is the adolescent population. Adolescents have shown interest in speaking with pharmacists about their medication use, demonstrating the importance for pediatric education in pharmacy schools. ${ }^{1,2}$ Active learning strategies are one way to effectively prepare student pharmacists to educate youth in the community about prescription opioids.

Pharmacy schools in the United States have recognized the usefulness of active learning with approximately $87 \%$ of PharmD programs reporting using these techniques. ${ }^{3}$ One approach is the use of educational games. Game-based learning activities are often used as a supplement to reinforce previously taught concepts, and debriefing post gameplay serves to solidify the lessons learned from the game. 4,5 Gamebased learning is a growing strategy for pharmacy educators to incorporate into their curriculum, and for pharmacists to use to educate the adolescents within the community.

Corresponding author: Olufunmilola Abraham, PhD, MS, BPharm, University of Wisconsin-Madison School of Pharmacy 777 Highland Avenue, Room 2515, Madison, WI 53705

Email: olufunmilola.abraham@wisc.edu

Phone: (608)263-4498
Students can gain the knowledge and skills regarding life-saving interventions to combat the current opioid crisis. ${ }^{6}$ With this goal in mind, some pharmacy programs have already begun to implement different active learning activities surrounding opioid intervention. One study evaluated the use of an interprofessional education event in which a patient panel, naloxone training, a patient simulation case, and a case study were used. $^{7}$ This intervention resulted in students scoring higher on a knowledge assessment, along with having an active conversation on difficult social issues surrounding opioids. ${ }^{7}$ Another study created a laboratory session that incorporated the active learning activities, naloxone consults, Prescription Drug Monitoring Program case discussions, and opioid dose conversion cases. This laboratory session was completed following a lecture on opioid overdose and naloxone. ${ }^{8}$ Students reported enjoying the laboratory session and felt that it prepared them well for encountering these topics in practice. ${ }^{8}$ One pharmacy school employed a curriculum taskforce to add six additional active learning opportunities focused on opioid education. ${ }^{9}$ After completing all the new opportunities students felt more comfortable consulting patients and helping determine opioid misuse potential. ${ }^{9}$

Despite these studies showing the importance of incorporating active learning, no studies show the impact that opioid oriented game-based learning can have on the knowledge of student pharmacists. One approach of implementing active learning is through the utilization of serious games, or games played for educational purposes (educational games). Serious games are advantageous for providing opioid education due to their interactive nature, excitement, and the creation of a less 
stressful environment. To the authors' knowledge, there are limited opportunities for interactive approaches for learning about opioid safety. Accordingly, game-based learning activities may be used to supplement and reinforce opioid safety education for pharmacy students.

\section{STATEMENT OF THE INNOVATION}

The lead author (OA) developed MedSMART: Adventures in PharmaCity (University of Wisconsin-Madison, USA), an educational game aimed to teach adolescents about prescription opioid safety. MedSMART was conceptualized using a serious game behavior change framework and youth feedback. ${ }^{10}$ The objective of the project was to explore student pharmacists' perspectives on design and implementation of this digital game.

\section{DESCRIPTION OF THE INNOVATION}

Second- and third-year student pharmacists in a Midwestern School of Pharmacy enrolled in an elective course titled 'Appropriate Use of Abused Drugs' participated in this project in April 2019. Students were eligible to participate if they were enrolled in the course and attended the lecture on opioid misuse and medication safety among adolescents. Nine students that did not attend the class session were unable to participate.

Following the lecture, there was a demonstration of the digital game, MedSMART: Adventures in PharmaCity. The game was developed by a team of researchers led by OA, which included pharmacists, physicians, game designers, game development experts, and student pharmacists. Players move through the game as an anthropomorphized character who finds themself navigating opioid safety after an injury. The game takes players through a series of levels that presents them with various dilemmas pertaining to opioid medication safety at home, in school or on a bus. The player must interact with others and their environment, and choose to use prescription opioids safely, to complete each level. The game aims to teach how to properly store, take, and dispose of medications. Additionally, it presents how to use naloxone in the event of an overdose. On consultation with the IRB, the project was determined to be quality improvement of the digital game; hence, IRB approval was not required.

Students' participation in the activity was mandatory for earning class credit. The students played the game individually on their personal computers for 30 minutes in small groups (four to six students) with one of the authors (OA, TT, MT) to participate in a 20 minute, semi-structured discussion using a question guide developed by the project team to explore reactions to each of the three game levels. The discussion guide asked questions about the game's purpose, what students liked or found confusing about each game level and changes they would recommend. Students worked as a group to create notes, summarize the group discussion, and submit their notes at the end of the class session. Names of participants were gathered following the discussion sessions and class rosters were used to determine year in school and gender. Personal identifiers were removed during data entry.

Discussion guide responses from students were thematically analyzed to create codes and categories that presented the major themes. Responses were open coded initially, and a master codebook was developed by three project team members (OA, MB, MT). Codes and the master codebook were reviewed by other members of the project team to ensure clarity and accuracy. Two team members (MB, MT) independently coded all discussion guide transcripts and developed initial codes. NVivo 12 qualitative software (QSR International, Australia) was used for the coding and codebook creation. Inter-rater reliability was moderate (kappa $=0.69$ ). Coding discrepancies were discussed and resolved during weekly team meetings. Prevalent codes were categorized and merged into four major themes to describe students' individual gameplay experience and small group assessment.

\section{CRITICAL ANALYSIS}

Following students' assessment of the game, four prevalent themes emerged and are presented in Table 1. Detailed, representative examples of verbatim quotes that relate to the themes and subthemes appear in Supplementary Table 1. Most respondents perceived that the purpose throughout all the levels of the game was to educate players on proper medication management. Respondents noted that the game introduced the concept of naloxone education and mentioned that sometimes people associate naloxone with street drugs. However, it is important to know that naloxone is an opioid overdose reversal for both prescription and street opioids. Respondents also commented on the importance of adolescents knowing methods for safely and securely storing medications to eliminate medication misuse. 
Table 1. Definitions of Themes and Subthemes

\begin{tabular}{|c|c|}
\hline Themes and Subthemes & Definitions \\
\hline \multicolumn{2}{|l|}{ Theme 1: Opioid safety education } \\
\hline Avoid medication misuse & $\begin{array}{l}\text { Prevent medication misuse such sharing medications with others, taking } \\
\text { medications that are not prescribed to you, and the responsibilities of } \\
\text { managing opioid medications }\end{array}$ \\
\hline Naloxone education & $\begin{array}{l}\text { Identifying a solution to an overdose by the use of naloxone by } \\
\text { demonstrating its value in emergency situations }\end{array}$ \\
\hline Safe medication storage & $\begin{array}{l}\text { Identifying proper storage techniques of opioid medications within the } \\
\text { home }\end{array}$ \\
\hline \multicolumn{2}{|l|}{$\begin{array}{l}\text { Theme 2: Engaging, interactive, and realistic game } \\
\text { design }\end{array}$} \\
\hline Engaging game design & $\begin{array}{l}\text { Overall appearance and layout of the game is important in holding } \\
\text { engagement }\end{array}$ \\
\hline Interactive game-play & $\begin{array}{l}\text { Ability for the player to take numerous paths throughout the game holds } \\
\text { engagement }\end{array}$ \\
\hline Realistic gameplay & $\begin{array}{l}\text { Ability for the player to relate and connect with the character and } \\
\text { different situations presented holds engagement }\end{array}$ \\
\hline \multicolumn{2}{|l|}{$\begin{array}{l}\text { Theme 3: Social interactions within gameplay } \\
\text { depicts decision making and consequences }\end{array}$} \\
\hline Peer pressure & Demonstrating how peer pressure can influence decision-making \\
\hline Consequences & $\begin{array}{l}\text { Demonstrates that every action taken has an outcome, positive or } \\
\text { negative }\end{array}$ \\
\hline \multicolumn{2}{|l|}{$\begin{array}{l}\text { Theme 4: Improve gameplay instructions and } \\
\text { dialogue }\end{array}$} \\
\hline Game controls and playable environments & $\begin{array}{l}\text { Include tutorials on how to successfully navigate the game while } \\
\text { highlighting key objects and gameplay boundaries }\end{array}$ \\
\hline Incorporate level objectives and summaries & $\begin{array}{l}\text { Include level objectives that direct the game and players with a common } \\
\text { purpose and summarize key points following each level completion, } \\
\text { whether players succeed or fail }\end{array}$ \\
\hline Game dialogue and structure & $\begin{array}{l}\text { Modify game dialogue to allow players control the rate and amount } \\
\text { presented matches and while using real life scenarios }\end{array}$ \\
\hline
\end{tabular}

Respondents identified that the game appearance, graphics, and storylines were elements that kept the players engaged. Although respondents had comments on to the challenge in identifying the overall objective of each game level, they found that they appreciated the complexity required to succeed in the game. They explained that the interactive nature of the game and option to take different paths kept them involved and interested. Realistic scenarios added to the complexity and provided an "ethical dilemma" that encouraged students to weigh positives and negatives of their actions in the game. Most respondents identified that when, the player can relate to the character and the situations, the player is more engaged. Respondents noted that the game portrayed the influence of peer pressure on the players' decision of misusing an opioid prescription. They also stated that, when being pressured into situations, it is important to stand up for your beliefs.

Respondents were asked to identify areas of confusion and in almost all group responses they commented on confusion about the controls of the game. They emphasized that it would be beneficial to have a pre-game tutorial to demonstrate the controls of the game. Many commented on how highlighting or making the playable items and locations more distinctive would eliminate confusion and hold interest. Numerous groups commented on the desire to have a stated objective for each level that would help lead the player through the game with an identified purpose. Respondents mentioned that recapping the level upon completion would be beneficial to solidify the learning objectives and key messages that were portrayed. Respondents also commented that the more time spent reading dialogue, the less they were engaged and interested. Respondents reported that the structure of the game could use improvements to further strengthen the gameplay and the overall message. Respondents identified that providing ways to let the player know the character's thoughts and considerations during each obstacle of the game would benefit the player when taking course of action.

\section{KEY ISSUES}

This project aimed to explore student pharmacists' perspectives on game-based learning to teach opioid medication safety. Project results indicated that student 
pharmacists were actively engaged and learned opioid safety education using a game-based learning activity. Additionally, students provided valuable feedback to improve the game content and design to further implement opioid safety education to adolescents. Introducing game-based learning in the pharmacy classroom represents an important step in enhancing pharmacy and interprofessional training on patient education, communication, social collaboration, and criticalthinking skills. The respondents were able to take away the overarching messages the game portrayed on appropriate drug use, while shedding light on opportunities to improve gameplay to facilitate learning about opioid medication safety.

\section{NEXT STEPS}

Future projects could aim to understand the influence of gamebased learning in the classroom at pharmacy institutions across the United States and internationally by exploring the perspectives and preferences of student pharmacists' method of learning. Additionally, future studies could seek to quantify and compare the retention rates of students from lectures and game-based learning activities held in pharmacy school classrooms.

\section{Conflicts of Interest: None}

Acknowledgements: The authors appreciate Sara Hassan for assisting with data collection and Lisa Szela and Kelsey Brasel for assisting with editing final drafts of the manuscript and providing feedback during data analysis.

Funding/Support: This study was supported by KL2 grant KL2 TR002374-03 and grant UL1TR002373 to UW ICTR by the Clinical and Translational Science Award (CTSA) program, through the NIH National Center for Advancing Translational Sciences (NCATS). The content is solely the responsibility of the authors and does not necessarily represent the official views of the NIH.

\section{REFERENCES}

1. Abraham O, Chmielinski J. Adolescents' misuse of over-the-counter medications: The need for pharmacist-led intervention. Innov Pharm. 2018;9(3):4. doi.org/10.24926/iip.v9i3.979.

2. Abraham O, Brothers A, Alexander DS, Carpenter DM. Pediatric medication use experiences and patient counseling in community pharmacies: Perspectives of children and parents. J. Am. Pharm. Assoc. 2017;57(1):38-46. doi: 10.1016/j.japh.2016.08.019.

3. Stewart DW, Brown SD, Clavier CW, Wyatt J. Activelearning processes used in US pharmacy education. Am J Pharm Educ. 2011;75(4):68. doi: 10.5688/ajpe75468.

4. Aburahma MH, Mohamed HM. Educational games as a teaching tool in pharmacy curriculum. Am J Pharm Educ. 2015;79(4):59. doi: 10.5688/ajpe79459.

5. Fanning R, Gaba D. The role of debriefing in simulation based learning. Simul Healthc. 2007;2(1):115-125. doi: 10.1097/SIH.0b013e3180315539.

6. Tannahill $N$, Tissington $P$, Senior $C$. Video games and higher education: what can "call of duty" teach our students? Front Psychol. 2012;3:210. doi: 10.3389/fpsyg.2012.00210.

7. Monteiro K, Dumenco L, Collins S, et al. An interprofessional education workshop to develop health professional student opioid misuse knowledge, attitudes, and skills. J Am Pharm Assoc (2003). 2017;57(2S):S113-S117. doi: 10.1016/j.japh.2016.12.069.

8. Donohoe KL, Raghavan A, Tran TT, Alotaibi FM, Powers KE, Frankart LM. A Laboratory Session to Prepare Pharmacy Students to Manage the Opioid Crisis Situation. Am J Pharm Educ. 2019;83(7):6988. doi: 10.5688/ajpe6988.

9. Werremeyer A, Skoy E, Marvanova M, et al. A PharmD program curricular approach to addressing the opioid crisis. Curr Pharm Teach Learn. 2019;11(6):592-602. doi: 10.1016/j.cptl.2019.02.026.

10. Abraham O, Thakur T, Brown R. Developing a theorydriven serious game to promote prescription opioid safety among adolescents: Mixed methods study. JMIR Serious Games. 2020;8(3). doi: 10.2196/18207. 